\title{
Opinião dos pais e resolução de conflitos por pré- adolescentes
}

\author{
Maria Isabel da Silva Leme \\ Universidade de São Paulo - São Paulo, SP, Brasil \\ Alysson Massote Carvalho \\ Universidade Federal de Minas Gerais - Belo Horizonte, MG, Brasil \\ Ilana Joveleviths \\ Universidade de São Paulo - São Paulo, SP, Brasil
}

\begin{abstract}
Resumo
O estudo visou a verificar se existe relação entre as estratégias de resolução de conflitos de préadolescentes e a percepção que têm das opiniões de seus pais sobre elas. Participaram 369 alunos do sexto e sétimo anos do Ensino Fundamental de três escolas, uma pública e duas privadas, que responderam a um questionário sobre a resolução de dez situações de conflito com colegas, amigos e pais. Foram acrescentadas questões em dois conflitos sobre opinião parental acerca da estratégia apresentada pelo participante. Os resultados mostraram que, no total da amostra, as estratégias predominantes de resolução foram submissão, coerção, mistas de coerção e submissão, e negociação, verificando-se diferenças entre tipo de escola quanto à predominância de cada estratégia de resolução, assim como em relação à percepção da opinião parental. A submissão, a ambivalente de submissão com coerção e a negociação foram apontadas como aprovadas pelos pais. A agressão foi apontada como reprovada. Verificou-se relação positiva entre estratégia relatada e percepção da opinião dos pais, assim como entre opinião e motivo.
\end{abstract}

Palavras-chave: Conflito, Estratégias, Percepção, Pais, Escola.

\section{Parents' opinions and interpersonal conflict resolution by preadolescents}

\begin{abstract}
The study aimed to verify possible relationships between preadolescents' strategies to solve interpersonal conflicts and their perception of parents' opinions about these strategies. 369 students participated, enrolled in the sixth and seventh grades of three schools, one public and two private. They answered an open questionnaire about their strategies to solve ten conflicts with colleagues, friends or parents. Questions concerning parental opinion about the proposed strategy were added in two conflicts. The results showed that the prevailing resolution strategies in the sample were submission, coercion, coercion mixed with submission, and negotiation. Differences were found between school types on the predominance of each resolution strategy, as well as in relation to the perception of parental opinion. The strategies perceived as approved by parents were submission, submission mixed with coercion, and negotiation. Aggression was pointed out as rebuked. Positive relationships were obtained between strategic choice and perception of parents' opinion as well as between opinion and motive.
\end{abstract}

Keywords: Conflict, Strategies, Perception, Parents, School.

Endereço para correspondência: Maria Isabel da Silva Leme. Instituto de Psicologia da Universidade de São Paulo. Avenida Professor Mello Moraes, 1721, Butantã. São Paulo/SP, Brasil. CEP: 05508-030. E-mail: belleme@usp.br. 


\section{Opinión de los padres y la resolución de conflictos por parte de pre adolescentes}

\section{Resumen}

El objetivo del estudio fue verificar si existe relación entre las estrategias de resolución de conflictos de los preadolescentes y la percepción que tienen de la opinión de sus padres sobre ellas. Participaron 369 estudiantes de sexto y séptimo años de educación básica de tres escuelas, una pública y dos instituciones privadas que respondieron a un cuestionario sobre la resolución de diez casos de conflictos con colegas, amigos y padres. Se añadieron cuestiones en dos conflictos relativas a la opinión de los padres sobre la estrategia propuesta. Los resultados mostraron que prevalecen la sumisión, la coerción, mesclas de coacción y sumisión, y la negociación en el total de la muestra, verificándose diferencias entre el tipo de escuela en relación al predominio de cada estrategia, así como en relación a la percepción de la opinión de los padres. La sumisión, la ambivalente de sumisión con la coerción y la negociación fueron aprobadas por los padres. La coerción fue identificada como no aprobada. Se verificó relación positiva entre estrategia y percepción de la opinión de los padres y así como entre la opinión y razón.

Palabras clave: Conflicto, Estrategias, Percepción, Padres, Escuela.

Ramos e Mizne (2011) relatam que, em 2006, o Brasil ocupava o quinto lugar entre 83 países na incidência de homicídios de jovens entre 15 e 24 anos. A maioria destas mortes seria consequência de conflitos ocorridos em finais de semana entre jovens do sexo masculino, sem antecedentes criminais. Estes dados indicam, no entender dos autores, a necessidade urgente de se educar os jovens para se relacionarem, para conhecerem outras alternativas de resolução de conflitos além do confronto violento com o outro.

No que diz respeito a estas alternativas de resolução, é importante observar, em primeiro lugar, que os conflitos aqui entendidos como situações de interação social se distinguem de outras interações pela ocorrência de algum tipo de oposição ou desacordo entre os envolvidos. Segundo Deluty (1979), pesquisador pioneiro no estudo das formas de resolução por crianças e adolescentes, os conflitos de interação social podem ser resolvidos de duas formas: o enfrentamento e a fuga, distinguidos de acordo com sua manifestação.

$\mathrm{O}$ enfrentamento violento caracterizado pelo uso de agressão física ou verbal, e o pacífico, mais desejável, se manifestaria em ações como negociação, conciliação de interesses, por ele denominadas asserção (assertion). Entretanto, como será analisado a seguir, esta forma de resolução é menos frequentemente encontrada que o confronto violento ou a fuga, por exigir tanto desenvolvimento cognitivo, como experiência via aprendizagem.
No que diz respeito ao desenvolvimento cognitivo, a resolução de conflitos é um processo complexo, que exige recursos cognitivos mais evoluídos (Vasconcellos, Picon, Prochnow, \& Chittó Gauer, 2006). Isto porque, ao se deparar com uma situação social que provoca emoção como o conflito, o indivíduo precisa processar e coordenar uma grande quantidade de informações, tais como: a identidade do opositor, no que consiste a oposição constatada, a intenção desta, emoção despertada, o quanto a ação do outro está de acordo com as normas vigentes na cultura, o que pode ser feito para resolver a situação, riscos envolvidos no enfrentamento da situação, direitos de cada parte envolvida (Ellsworth, 1994).

Quanto ao papel da experiência, o contexto em que esta ocorre tem sido destacado como importante. Nesta perspectiva, a cultura tem sido apontada como uma variável relevante para a resolução de conflitos no que diz respeito à escolha de estratégias, condicionada pelos valores compartilhados no grupo, no caso do conflito, aqueles relativos à convivência (Leme, 2006). Nas culturas identificadas como coletivistas, como as orientais e latinas, onde a harmonia entre os membros do grupo é valorizada, as estratégias de esquiva ao conflito ou de conciliação entre as partes são mais observadas do que as de confronto. Já nas culturas individualistas, como as europeias e norte-americana, onde os direitos individuais são mais valorizados do que a convivência com o grupo, são observadas mais estratégias de 
enfrentamento, inclusive de confronto com a outra parte (Bergeron \& Schneider, 2005; Martinez-Lozano, Sánchez-Medina, \& Goudena, 2011).

A experiência proporcionada pela socialização é considerada por muitos autores (Ramos \& Mizne, 2011; Grusec \& Goodnow, 1994; Baumrind, Larzelere, \& Owens, 2010) um fator essencial para o uso de estratégias mais construtivas, como por exemplo, a negociação. De acordo com esta perspectiva, as práticas de socialização precisam ser adequadas no sentido de prover experiências e modelos que levem ao desenvolvimento de formas mais construtivas de lidar com o conflito.

Baumrind, precursora na investigação destas práticas, identificou três tipos de formas de lidar com conflitos, diferenciados de acordo com o grau de controle e afetividade manifestada: autoritária, autoritativa (ou democrática) e permissiva ${ }^{1}$. A primeira se define pelo alto controle da conduta e pouca demonstração de afetividade positiva, a segunda se diferencia pelo controle adequado, em que os motivos para as regras são explicados, e afetividade demonstrada é positiva, e a permissiva se caracteriza pela ausência de controle, mas também pela demonstração de afetividade positiva.

As primeiras pesquisas (Baumrind \& Black, 1967; Baumrind, 1971) já apontavam relação entre $o$ estilo de criação e a competência social da criança, no caso, o autoritativo relacionado à autonomia, ajustamento e segurança da criança já na préescola. A explicação para esta associação seria que as práticas democráticas servem como modelos de conduta para os filhos, assim como estimulam o enfrentamento das situações de modo construtivo (Baumrind et al., 2010). A relação entre práticas autoritativas ou democráticas e melhores resultados desenvolvimentais, assim como a associação das autoritárias e permissivas a problemas também foi encontrada por outros pesquisadores (Darling, Cumsille, \& Martínez, 2008; Baumrind et al., 2010).

Uma possível explicação para esta associação seria que a interpretação da autoridade parental, quando é considerada indicativa de cuidado, leva a maior aceitação do

\footnotetext{
${ }^{1}$ Esta última posteriormente refinada por Maccoby e Martin (Maccoby, 1984) em negligente e indulgente.
}

controle (Grusec, 2011). Porém, alguns autores, como Ramos e Mizne (2011), parecem considerar que as práticas atuais já não se diferenciam umas das outras no que diz respeito ao exercício do controle dos filhos, pois consideram que está ocorrendo uma crise de autoridade, tanto na família, como na escola, o que explicaria os altos índices de violência mencionados acima.

Esta visão de autoridade em crise na educação não é consenso e envolve a consideração de outras variáveis, além do exercício do controle pelos pais, como se examinará a seguir. Gheorghiu, Gruson e Vari (2008) ponderam que as relações entre pais e filhos tornaram-se mais democráticas, acompanhando o mesmo movimento na sociedade. Salientam ainda que, para que a socialização se efetive no sentido da boa convivência social, como a resolução de conflitos por meio da negociação, é preciso que as práticas de criação neste contexto mais democrático não se limitem a conceder mais liberdade, mas busquem a formação ética dos filhos, levando-os a prezar valores como respeito e justiça na relação com o outro.

Vale lembrar, a respeito desta adesão aos valores familiares, que Turiel (2008) demonstrou, já na década de 1980, que a legitimidade conferida pelos filhos à autoridade dos pais depende do domínio a que se refere: se pessoal, como escolha de vestuário; convencional, como regras de conduta na escola, segurança, como obediência a horários, ou ainda, moral, o mais relacionado à resolução de conflitos. O controle sobre a conduta relativa aos dois últimos domínios tende a ser mais legitimado do que o pessoal, mas também diminui com a idade. Turiel (2008) aponta que já entre 4 e 6 anos as crianças não confundem questões morais com as não morais. A hipótese é que altos níveis de controle comportamental em domínios vistos como legítimos previnem problemas de conduta.

Montandón (2005) também questiona a existência de crise de autoridade na família, argumentando que a questão é bastante complexa. A seu ver, mesmo que as práticas de criação tenham se tornado mais democráticas, a formação ética não se restringe à adesão dos filhos aos valores familiares. Isto porque esta adesão é um fenômeno influenciado por múltiplas variáveis, como se pode constatar pelas pesquisas que buscaram estabelecer vínculos causais entre a conduta dos filhos e a 
adoção das práticas de criação identificadas por Baumrind (1971), no caso, as já mencionadas: autoritária, autoritativa ou democrática e permissiva. A seu ver, fatores como cultura, nível socioeconômico, características da criança - como temperamento - conferem complexidade ao fenômeno, interagem e produzem resultados diversos.

Assim, nas culturas coletivistas, onde a harmonia no grupo é valorizada, as práticas autoritativas ou democráticas não produzem resultados tão positivos como nas individualistas, aonde este aspecto da relação é menos importante. Neste sentido, Montandón (2005), defende que é necessário pesquisar a influência do estilo de criação a partir da perspectiva da criança, pois ela seleciona, interpreta as experiências e constrói estratégias, neste contexto complexo, que podem, inclusive, produzir mudanças em suas relações com os pais e revisões nas práticas de criação.

Este ponto de vista é partilhado por Arim, Marshall e Shapka (2010), que argumentam na mesma direção, ao defender que os efeitos das práticas de criação são avaliados mais acuradamente por meio da percepção do controle relatada pelos filhos do que por observações destas em ação. Ohene, Ireland, Mc Neely e Borowsky (2006) relatam resultados sobre outras esferas da vida além da resolução de conflitos, mas que valem ser relatados por demonstrar a complexidade envolvida na avaliação dos efeitos das práticas parentais e, também, por corroborar o argumentado sobre a importância da percepção do controle pelos filhos.

Os autores observaram que a revisão da literatura indicou que as expectativas percebidas nos pais correlacionam mais com as condutas dos adolescentes relativas à sexualidade do que as que eles mesmos informam. No que diz respeito à resolução de conflitos, os mesmos autores verificaram que a percepção de desaprovação do uso de violência pelos pais relaciona-se a atitudes pró-sociais dos filhos. A pesquisa a ser relatada procurou justamente verificar esta percepção, por meio de relatos de pré-adolescentes sobre a opinião de seus pais no que diz respeito à sua forma de resolução de conflitos.

Outro aspecto identificado pelas pesquisas como importante, mas também controverso, no exercício da autoridade parental é como ela é exercida, se por meio de controle do comportamento dos filhos, ou por meio de controle psicológico. Este último é visto como prejudicial (Kakihara \& Tilton-Weaver, 2009), pois se baseia em manipulação de emoções, por meio de estratégias como indução de culpa, retirada de amor, etc. As consequências de cada tipo de controle são diferentes: a ausência do comportamental tende a produzir problemas externalizantes, como agressividade, enquanto o exercício do psicológico favoreceria o surgimento de problemas internalizantes, como depressão.

Entretanto, os autores ponderam, como Arim et al. (2010), que há certo artificialismo nesta distinção, e que é necessário verificar as crenças dos filhos sobre o controle, em que domínios a interferência dos pais é considerada legítima, entre outros aspectos, coincidindo com a perspectiva de autores examinada acima (Montandón, 2005; Gheorghiu et al., 2008).

A percepção de controle parental também é influenciada pelo nível socioeconômico, como verificaram Lins-Dyer e Nucci (2007) em nosso meio. Os autores compararam em 2 níveis socioeconômicos, diferentes quanto ao maior ou menor poder aquisitivo, as percepções de controle de díades de mães e filhas entre 11 e 16 anos. Estas percepções foram obtidas por meio de respostas a questionários aplicados na escola. Foram encontradas diferenças entre os 2 níveis socioeconômicos, como percepção de maior controle no menos afluente, principalmente em questões envolvendo segurança, possivelmente em função de percepções das mães de maior risco no ambiente. Como em outros estudos, verificouse semelhança entre os níveis socioeconômicos no que diz respeito ao direito à autonomia em questões da esfera pessoal, legitimando-se a autoridade das mães só nas questões de segurança e convencionais.

Outros efeitos do nível socioeconômico também foram encontrados por Custódio e Cruz (2008) no que diz respeito às representações mentais das crianças acerca das figuras parentais, importantes porque dirigem a interação, na medida em que geram antecipações sobre o outro. Verificou-se que no nível socioeconômico menos afluente, os pais foram representados de modo mais negativo, como figuras mais punitivas, que explicitam menos suas expectativas a respeito da conduta dos filhos, e que estas representações relacionaram-se por um lado, a menor autocontrole, assertividade e competência escolar, e, por outro, a mais problemas 
internalizantes (tristeza, ansiedade, autoestima negativa).

Já a representação de práticas disciplinares verbais (instrução/explicação/indução) correlacionou-se com maior assertividade. Os resultados relativos a estas diferenças entre níveis socioeconômicos interessam ao presente estudo porque esta variável tem se revelado importante na resolução do conflito interpessoal, encontrando-se maior tendência nos níveis menos afluentes a resolver os conflitos de modo submisso ou agressivo do que nos mais afluentes, que empregam mais estratégias assertivas do que nos primeiros (Leme, 2004, 2006).

Finalmente, uma variável que também tem sido identificada como importante na resolução de conflitos é o sexo dos envolvidos. As pesquisas (Ballif-Spanvill, Clayton, \& Hendrix, 2003; Leme, 2004; Noakes \& Rinaldi, 2006; Kikas, Peets, Troop, \& Hinn, 2009) tem encontrado maior tendência do sexo masculino do que o feminino a resolver os conflitos de modo violento, o que tem sido atribuído a maior permissividade quanto a este aspecto nas práticas de socialização dos meninos. Estes resultados contrastam com os encontrados em nosso meio por Sampaio e Vieira (2010), que encontraram diferenciação de práticas segundo $\mathrm{o}$ gênero dos filhos quanto à exigência e manutenção das regras. Os autores verificaram que os pais se mostraram mais exigentes com os filhos do que com as filhas, o que indica maior investimento parental no sexo masculino do que no feminino. Não foram localizadas pesquisas que investigassem como cada sexo percebe a autoridade parental, nem se as legitima.

Verifica-se, a partir do exposto, que a relação entre práticas educativas adotadas pela família e a conduta dos filhos é bastante complexa, sofrendo a influência de muitas variáveis que interagem entre si, como o tipo de prática adotada, cultura, contexto socioeconômico em que ocorre a educação, o domínio a que se refere, se moral, pessoal, convencional ou de segurança, aspirações da família para os filhos e características destes, como desenvolvimento psicológico, idade, temperamento e sexo.

Tendo em vista esta multiplicidade de fontes de influência, várias pesquisas aqui revistas recomendam que o estabelecimento de relações entre práticas de socialização e conduta, como, por exemplo, a relação apontada anteriormente (Ramos \& Mizne, 2010) entre uso de violência na resolução de conflitos e crise de autoridade, seja investigado sob o ponto de vista dos filhos, o que foi realizado na presente pesquisa. Além disso, não foram encontrados, na revisão da literatura, trabalhos conduzidos em nosso meio que buscassem esclarecer se há relação entre o que os filhos percebem como sendo a opinião de seus pais e a seleção de estratégias de resolução de conflitos.

Valem ser citados trabalhos que estabelecem relação entre percepção de estilo parental, problemas de comportamento e competência social (De Salvo, Silvares, \& Toni, 2005), relação entre práticas parentais e envolvimento em conflito com a lei (Carvalho \& Gomide, 2005), relação entre prática parental e conduta moral relativa à honestidade dos filhos (Prust \& Gomide, 2007), relação entre autonomia dos filhos com as práticas adotadas pelos pais (Reichert \& Wagner, 2007), a estabilidade das práticas entre gerações (Weber, Selig, Bernandi, \& Salvador, 2006), e ainda estudos dedicados ao desenvolvimento de instrumentos para aferir esta dimensão da socialização.

A este respeito, valem também ser mencionados dois instrumentos disponíveis no Brasil. O Inventário de Estilos Parentais, aprovado pelo Conselho Federal de Psicologia como instrumento de diagnóstico, que foi desenvolvido por Gomide em uma perspectiva teórica diferente da de Baumrind, mas que aborda muitas das mesmas dimensões, como tipo de monitoramento e afetividade e tem encontrado resultados semelhantes, como por exemplo, monitoria positiva associada à sociabilidade (Prust \& Gomide, 2007; Sampaio \& Gomide, 2007; Carvalho \& Gomide, 2005).

Duas escalas foram traduzidas e adaptadas nas dimensões de responsividade e exigência (Costa, Teixeira, \& Gomes, 2000; Teixeira, Oliveira, \& Wottrich, 2006), encontrando semelhanças entre a amostra norte-americana e a brasileira. Porém, um aspecto que interessa a esta pesquisa diz respeito à relação entre a avaliação das práticas pelos pais e filhos, tendo sido encontrada discordância entre eles (Costa et al., 2000), o que coincide com resultados encontrados por outros autores (Weber, Prado, Viezzer, \& Brandenburg, 2004), que corrobora mais uma vez a importância de se investigar as práticas por meio da percepção dos filhos. 
Tendo em vista a lacuna constatada na literatura, consideramos importante investigar a relação entre a percepção da opinião dos pais e a escolha de estratégia de resolução de conflitos pela associação estabelecida entre crise de autoridade dos agentes de socialização e a mortalidade de jovens envolvidos em conflitos no Brasil. Assim, o objetivo principal da pesquisa aqui apresentada foi investigar se há relação entre a percepção da opinião dos pais e a seleção da estratégia usada em resolução de conflitos interpessoais por pré-adolescentes.

\section{Método}

\section{Participantes}

Fizeram parte da pesquisa 369 alunos que cursavam o sexto e sétimo anos do segundo ciclo do Ensino Fundamental de três escolas, duas situadas na zona oeste da cidade de São Paulo e uma no interior de Minas Gerais. Uma das escolas de São Paulo é pública, mantida pelo município e a outra é privada. A escola mineira é privada, e o poder aquisitivo dos alunos semelhante aos da paulistana particular. Dentre os 156 alunos da escola municipal paulistana, $46 \%$ eram do sexo feminino, $54 \%$ do masculino, sendo que $47 \%$ cursavam o sexto ano e $53 \%$ o sétimo. $\mathrm{Na}$ escola privada paulistana, da qual participaram 82 alunos, $48 \%$ eram do sexo feminino e $52 \%$ do sexo masculino. Destes, $54 \%$ cursavam o sexto ano e $46 \%$ o sétimo. Quanto aos 131 alunos da escola mineira, $40 \%$ eram do sexo feminino e $60 \%$ do masculino, $49 \%$ frequentavam o sexto ano e o restante $(51 \%)$ o sétimo. A idade média dos alunos de escola pública era 12 anos e nas privadas, 10,9 anos na paulistana e 11, 9 anos na mineira.

\section{Instrumento}

O material utilizado para a presente pesquisa foi a versão em português do questionário aberto desenvolvido e cedido por Robert Deluty (Deluty, 1979), já usado em outras investigações (Leme, 2004, 2006; Vincentin, 2009). O questionário traz 10 breves descrições de conflitos em que o participante é descrito como o protagonista alvo de ações como provocação, frustração, praticadas por uma ou mais pessoas, variáveis quanto ao grau de proximidade, colegas, amigos ou pais. A descrição é seguida pela pergunta: "O que voce faria?".
Para atender aos objetivos da pesquisa de verificar a relação entre as estratégias de resolução do conflito informadas pelos participantes e a percepção das opiniões dos pais, foram acrescentadas ao questionário perguntas sobre: situação familiar, companhias de lazer, opinião dos pais e professores a respeito das estratégias escolhidas em dois conflitos, conselho provável dos pais em uma situação de bullying e sentimentos despertados por sete situações de conflito.

As situações em que foi solicitada a percepção dos pais e professores foram selecionadas a partir dos seguintes critérios: 1) os protagonistas descritos como provocando o conflito não serem os pais; 2) a maior probabilidade das respostas dos participantes despertarem opinião destes, em função das reações a eles já verificadas como as mais frequentes serem a submissão ou agressão (Leme, 2004); 3) a avaliação de dez crianças da mesma idade dos participantes sobre a adequação destas situações obtida em um estudo piloto. As duas situações de conflito selecionadas para pesquisar a opinião dos pais e professores foram a humilhação pública provocada pela caçoada de amigos sobre o desempenho do participante em um jogo e ser empurrado para fora da fila da cantina por um colega, cuja intenção não é especificada.

Nestas duas situações foram acrescentadas questões sobre o que os pais e professores achariam da reação do participante, e o motivo para tal. Cabe relatar que Custódio e Cruz (2008) não encontraram diferenças entre as representações das figuras paterna e materna na resolução de conflitos hipotéticos com o pai ou com a mãe, verificando-se a tendência em representá-los como uma única unidade parental, o que fundamentou nesta pesquisa a formulação da pergunta sobre a sua opinião sem especificá-los. Tendo em vista a grande quantidade de dados obtidos, neste artigo só serão tratados os dados relativos à situação familiar, lazer, estratégias de resolução e opinião dos pais.

\section{Procedimento}

A aplicação do questionário foi realizada pelos pesquisadores em sala de aula, em horários disponibilizados pelos professores, aos quais se solicitou que não permanecessem na classe durante a aplicação para não constranger os alunos. Os alunos foram assegurados que podiam escolher se desejavam ou não participar 
da pesquisa, e que nenhuma pessoa da escola teria acesso às informações prestadas, para que estas correspondessem ao que realmente fariam nas situações descritas no instrumento. A aplicação durou cerca de 40 minutos. O procedimento utilizado foi aprovado pelo Comitê de Ética da instituição dos pesquisadores.

\section{Análise dos dados}

As questões relativas às estratégias para resolver os conflitos, assim como a opinião presumida dos pais foram formuladas de modo aberto, como exemplificado anteriormente sobre a estratégia, para garantir que não induzissem a resposta dos participantes. Como já especificado, foi perguntado ao final de cada descrição de conflito: O que você faria? O que você sentiria? E no caso dos dois conflitos selecionados: O que seus pais achariam do que você fez e por quê? As respostas dos alunos aos conflitos, em termos das estratégias que usariam foram categorizadas seguindo dois critérios já utilizados anteriormente, coerentes com os de Deluty especificados acima (Leme, 2004, 2006; Vincentin, 2009), sendo o primeiro a ocorrência de enfrentamento ou não do conflito, e o segundo, o tipo de conduta envolvida no enfrentamento, coercitiva ou pacífica.

Assim, as categorias de respostas foram: estratégias de fuga e esquiva ao conflito, como por exemplo, ausência de reação ou obediência, aqui denominadas submissas. As estratégias de enfrentamento foram analisadas de acordo com a conduta adotada: se envolvia alguma forma de coerção física ou psicológica, aqui denominadas agressivas, ou se a ação adotada consistia em enfrentamento pacífico, como tentativas de negociação ou conciliação, aqui denominadas assertivas. Vale observar que da mesma forma que em pesquisas anteriores, foram encontradas estratégias mistas, combinando mais de um tipo de reação ao conflito, como por exemplo, agressivas e submissas.

As respostas sobre a percepção da opinião dos pais foram categorizadas de acordo com dois critérios: especificação de opinião (aprovação, desaprovação, sem consenso) ou ausência de especificação (não opinariam, não saberiam opinar, não ficariam sabendo do ocorrido). As explicações para tal opinião foram categorizadas de acordo com os seguintes critérios: menção explícita a orientações parentais, menção a reações dos pais (sentimento pelo participante, pelo seu ato, sentimento pelo incidente/provocação).

Tanto as categorizações das estratégias, como das reações dos pais foram avaliadas por um psicólogo que classificou segundo os critérios acima cerca de um quinto de respostas selecionadas por sorteio. Foi obtido um índice de concordância de $92 \%$ entre as duas avaliações independentes, resolvendo-se as discordâncias posteriormente.

Em virtude da natureza dos dados, a análise estatística para verificar a existência de relação entre a escolha da estratégia e a opinião percebida foi realizada com testes não paramétricos, adotando-se um nível de significância de 5\% para o intervalo de confiança de 95\%, buscando-se assim verificar relação entre as seguintes variáveis, tipo de estratégia, percepção da opinião dos pais, tipo de escola e sexo do participante.

\section{Resultados}

\section{Caracterização da amostra}

Como informado anteriormente, por ser objetivo deste estudo verificar a relação entre a escolha de estratégias de resolução de conflito pelos alunos e a sua percepção da opinião dos pais, foram acrescentadas ao questionário perguntas sobre sua situação familiar, sua relação com a escola, principais companhias de lazer, entre família, amigos e colegas, de modo a favorecer a compreensão dos resultados. Em relação à constituição familiar dos alunos, foi possível constatar diferenças relacionadas ao tipo de escola, pública ou privada.

Em outras palavras, alunos de escolas privadas assemelharam-se mais entre si quanto à situação familiar, diferindo dos de escola pública, pois como pode ser observado na Tabela 1 , verificou-se que a grande maioria dos primeiros mora com a família nuclear biparental, o que ocorre com menos da metade dos alunos de escola pública, onde menos da metade mora com a família nuclear biparental. Além disso, como se pode observar na Tabela 1 , verifica-se maior probabilidade de que os alunos de escola pública experimentem maior variabilidade nas potenciais fontes de influências familiares do que a maioria dos outros participantes de escolas privadas, pois o contingente que vive com a família extensa, com ou sem os pais, é mais que o dobro do que nas outras escolas. 
Tabela 1 - Constituição familiar segundo o tipo de escola e local

\begin{tabular}{lccc}
\hline Família / Escola & Privada SP $\%$ & Privada MG \% & Pública SP \% \\
\hline Nuclear Bipar & 75 & 75 & 41 \\
Nuclear Mono & 16 & 8 & 18 \\
Reconstituída & 1 & 6 & 10 \\
Extensa c/pais & 4 & 11 & 26 \\
Extensa s/pais & 2 & 2 & 4 \\
\hline
\end{tabular}

Outra diferença relativa às condições de vida de acordo com o tipo de escola frequentada diz respeito às companhias de lazer dos participantes. Como pode ser observado na Tabela 2, quase metade dos alunos de escola pública tem somente a família como companhia de lazer, o que pode representar menor oportunidade de contato e estabelecimento de vínculos de amizade com colegas em outros contextos fora da escola. Por sua vez, tal diferença pode influir sobre a incidência e resolução de conflitos. A maioria dos demais participantes, principalmente da escola privada paulistana, costuma ter como companhia de lazer a família e amigos.

Tabela 2 - Proporção de companhia de lazer segundo o tipo de escola e local

\begin{tabular}{lccc}
\hline Companhia / escola & Privada SP \% & Privada MG \% & Pública SP \% \\
\hline Só família & 7 & 20 & 43 \\
Família+amigos e/ou colegas & 81 & 74 & 42 \\
Só amigos & 10 & 6 & 12 \\
Não respondeu & 2 & & 3 \\
\hline
\end{tabular}

\section{Estratégias de resolução de conflito e sentimentos}

No que diz respeito à caracterização da amostra em termos de preferência por um tipo de estratégia, verificou-se que a submissão é a que foi preponderante, concentrando quase metade das respostas (40\%). Foi seguida pela coação ou agressão (18\%), que por sua vez suplantou duas equivalentes em incidência, as mistas de submissão e agressão (16\%) e assertivas (16\%). As demais, mistas de assertivas com submissão e assertivas com agressão, obtiveram proporções bem mais baixas de escolha, $4 \%$ e $6 \%$ respectivamente. Estes resultados coincidem com encontrados anteriormente em estudos realizados com o mesmo instrumento, respondido por amostras da mesma idade de escolas públicas e privadas (Leme, 2004; Vincentin, 2009).

Os sentimentos despertados pelas situações foram em sua maioria negativos $(72 \%)$, sendo tristeza e raiva os mais frequentemente apontados. Em seguida, foram relatados ausência de sentimento (17\%), sensação física, como dor ou fome (5\%) e sentimento positivo (4\%).

\section{As estratégias de resolução segundo $o$ tipo de conflito}

Coerentemente com o apontado na caracterização da amostra em termos de incidência das estratégias, em que se constatou a preponderância da submissão, verificou-se ainda que ela foi a de maior incidência em sete das dez situações de conflito apresentadas. Como pode ser observado na Tabela 3 , onde podem ser observadas estas frequências em cada escola, as respostas submissas suplantaram todas as demais estratégias, principalmente entre alunos de escola privada mineira e pública paulistana, nas seguintes situações: perder o prêmio de um jogo por apenas um ponto, recusa de um amigo ao pedido de partilha de um doce.

A submissão preponderou ainda nas mesmas escolas na situação de recusa de um grupo de colegas para participar de um jogo, e na de ser frustrado pelos pais que interrompem 
um programa de TV julgado impróprio. Em seguida, dois conflitos equivaleram na incidência de respostas submissas (42\%). Um deles foi sofrer crítica de um colega sobre a própria inteligência, e o outro foi ser atingido na cabeça por uma bola atirada por uma criança menor. Finalmente, em último lugar na prevalência de estratégias submissas sobre as demais, ficou o conflito causado pela humilhação pública, infligida por um grupo de amigos pelo mau desempenho do participante em um jogo.

Por outro lado, como mostra a Tabela 4 , as respostas agressivas preponderaram em duas situações de conflito. Uma descrevia a devolução por um amigo do participante do seu livro preferido danificado e a outra ser empurrado para fora da fila da cantina por um colega. Como pode ser verificado na Tabela 4, as maiores incidências deste tipo de resposta foram encontradas nas escolas paulistanas. Por fim, em um conflito criado pela ameaça de castigo dos pais em consequência da desordem feita por um amigo na casa, a estratégia mais selecionada pela amostra como um todo foi a mista de agressão com submissão, mais frequente na escola pública paulistana (49\%), seguida pelas privadas, mineira (43\%) e paulistana (34\%).

Em suma, na maioria dos conflitos, a tendência mais encontrada na amostra como um todo é evitar o confronto, ou não reagindo, ou obedecendo ao outro em $70 \%$ das situações descritas no instrumento. É interessante observar que entre os alunos da escola privada paulistana, esta tendência a evitar o conflito é sempre menos frequente que nas outras escolas, mineira e pública, assim como o uso da estratégia mista de agressão com submissão. $\mathrm{Na}$ situação em que esta reação ao conflito com os pais sobre a desordem na casa foi predominante nas outras duas escolas, um quinto dos participantes da privada paulistana indicou estratégias submissas.

Outro conflito que distinguiu esta escola foi o da humilhação pública por jogar mal, em que se diferenciaram na preferência por estratégias assertivas em relação às outras estratégias como submissão, mais apontadas pelos alunos das outras duas escolas. Os alunos de escola pública se destacam, por sua vez, pela maior proporção de escolha de estratégias agressivas do que os das duas escolas privadas, enquanto os da mineira lideram na maior incidência de estratégias submissas em cinco conflitos. O teste Kruskal-Wallis foi aplicado para verificar se as diferenças entre escolas são significativas, o que foi confirmado para as duas escolas privadas, paulistana e mineira, como mostra a Tabela 5 .

Tabela 3 - Proporção das respostas submissas predominantes em cada tipo de escola

\begin{tabular}{lccc}
\hline & Pública SP $\%$ & Privada SP $\%$ & Privada MG \% \\
\hline Perda prêmio & 82 & 74 & 75 \\
Recusa doce & 64 & 60 & 70 \\
Recusa jogar & 55 & 40 & 63 \\
Interrupção TV & 46 & 23 & 56 \\
Crítica colega & 36 & 34 & 53 \\
Bolada & 43 & 35 & 44 \\
Caçoada jogo & 39 & 30 & 38 \\
\hline
\end{tabular}

Tabela 4 - Proporção de respostas agressivas predominantes em cada tipo de escola

\begin{tabular}{lccc}
\hline & Pública SP $\%$ & Privada SP $\%$ & Privada MG \% \\
\hline Livro danificado & 46 & 36 & 35 \\
Empurrão na fila & 43 & 36 & 33 \\
\hline
\end{tabular}

Tabela 5 - Média dos Postos em cada escola e Teste de Kruskal-Wallis

\begin{tabular}{lccc}
\hline & Pública SP & Privada SP & Privada MG \\
\hline Média dos Postos & 1832,28 & 1937,58 & 1785,12 \\
\hline $\mathrm{p}=0,004$ & & &
\end{tabular}




\section{O uso de cada estratégia por cada sexo}

$\mathrm{Na}$ presente pesquisa, diferenças relativas ao sexo na preferência por determinado tipo de estratégia (Balif-Spanvill, Clayton, \& Hendrix, 2003) só ocorreram em dois conflitos, e não foram significativas segundo o teste Mann Whitney, como mostra a Tabela 6 . No conflito em que ocorreu maior diferença, do empurrão dado por colega, as alunas escolheram em menor proporção as estratégias agressivas do que os alunos (respectivamente $30 \%$ e $42 \%$ ). Já no conflito da perda do prêmio por um ponto, as alunas escolheram mais estratégias submissas que os alunos $(82 \%$ e $74 \%$ respectivamente). Por outro lado, a incidência de estratégias submissas entre alunas foi menor que a dos alunos no conflito do pedido recusado por colegas para participar de um jogo (alunas: 49\% e alunos: 60\%), pois apelaram mais para estratégias mistas de agressão com submissão (17\%) do que eles (10\%).

Quanto ao relato de sentimentos que seriam provocados pelas situações, ocorreram diferenças só nos conflitos causados pela crítica de colega à inteligência (alunas $51 \%$ e alunos $38 \%$ ), na ameaça de punição parental pela falta alheia (alunas 98\% e alunos 86\%), e na devolução do livro favorito danificado (alunas $97 \%$, alunos $85 \%$ ), em que as alunas relatam maiores proporções de sentimento negativo do que os alunos.

Tabela 6 - Média dos postos e Teste U de Mann Whitney para diferença entre sexos

\begin{tabular}{lccc}
\hline & Pública SP & Privada SP & Privada MG \\
\hline Soma dos Postos Feminino & 54982,00 & 165292,50 & 403399,00 \\
Soma dos Postos Masculino & 652133,00 & 171317,50 & 451379,00 \\
Mann Whitney U & 297487,000 & 82907,500 & 212746,00 \\
Z &,- 084 &,- 332 &,- 018 \\
\hline
\end{tabular}

\section{A percepção da opinião de pais sobre as estratégias selecionadas}

No que diz respeito à percepção da opinião dos pais sobre as suas estratégias de resolução, vale lembrar que, no primeiro conflito em que esta informação foi solicitada, que descreve o participante exposto a uma situação de humilhação pública por jogar mal, mais de um terço das respostas $(37 \%)$ incidiu na categoria de submissão, salvo na escola privada paulistana, onde a mais frequente foi a assertiva, e a segunda a submissão, como pode ser observado na Tabela 7. A segunda estratégia mais frequente na escola pública paulistana foi a mista de agressão com submissão, enquanto na escola privada mineira foi a assertiva, pouco maior que as mistas de agressão e submissão.

A grande maioria dos participantes (73\%), principalmente alunos das duas escolas privadas, informou acreditar que seus pais aprovariam suas estratégias, como pode ser observado na Tabela 8 , que apresenta as proporções da opinião parental percebida sobre cada estratégia na amostra como um todo. Como pode ser verificado na referida tabela, as estratégias percebidas como mais aprovadas foram as submissas e as assertivas, enquanto a agressão é percebida como reprovada. É interessante observar que as respostas assertivas e as mistas de submissão com agressão são objeto de maior variação de opinião dos alunos, pois são apontadas como as únicas que provocariam discordância entre os pais, principalmente as assertivas.

O teste qui quadrado mostrou associação positiva $\left(X^{2}=98,196^{\mathrm{a}} ; p<0,05\right)$ entre percepção de aprovação ou ausência de manifestação dos pais para escolha da submissão, percepção de desacordo entre eles para seleção de respostas assertivas e percepção de desaprovação para uso da agressão. É importante lembrar a este respeito que as respostas assertivas constituíram a segunda estratégia mais frequentemente escolhida (22\%) para lidar com este conflito, mas a maioria das respostas que a indicaram (67\%), informaram que a opinião dos pais sobre ela não seria consensual. $\mathrm{O}$ teste qui quadrado não evidenciou diferença significativa entre escolas e sexos no que diz respeito à opinião percebida nos pais e o uso destas estratégias neste conflito. 
Tabela 7 - Proporção de estratégias em cada escola no conflito da humilhação

\begin{tabular}{lccc}
\hline & Pública SP $\%$ & Privada SP\% & Privada MG\% \\
\hline Submissas & 39 & 30 & 38 \\
Agressivas & 18 & 14 & 14 \\
Assertivas & 16 & 35 & 20 \\
Mistas ag+sub & 22 & 5 & 18 \\
Mistas ag+as & 0,6 & 6 & 3 \\
Mistas as+sub & 1 & 10 & 6 \\
\hline
\end{tabular}

Tabela 8 - Proporção de percepção da opinião parental sobre estratégias da amostra no conflito da humilhação

\begin{tabular}{lcccc}
\hline & Aprovaria \% & Desaprovaria \% & Não opinariam \% & Desacordo \% \\
\hline Submissa & 41 & 21 & 43 & \\
Agressiva & 5 & 50 & 25 & \\
Assertiva & 27 & 4 & 7 & 67 \\
Sub+agr & 16 & 19 & 21 & 33 \\
Ass+agr & 3 & 5 & & \\
Ass+sub & 7 & 1 & 4 & 100 \\
& 100 & 100 & 100 & \\
\hline
\end{tabular}

As proporções de opiniões percebidas nos pais, segundo o tipo de escola frequentada, podem ser observadas na Tabela 9. Como se pode verificar nesta tabela, é mais frequente que alunos de escola privada considerem que sua estratégia seria aprovada pelos pais do que os alunos de escola pública. Coerentemente, os alunos de escola pública acreditam mais frequentemente do que os de escola privada que sua estratégia seria reprovada pelos pais.

Como mostra a Tabela 10, um contingente expressivo de alunos, principalmente de escolas privadas mineira $(63 \%)$ e paulistana $(57 \%)$ alegou que a opinião se deveria à correspondência entre a estratégia escolhida e a que seria recomendada pelos pais. $\mathrm{Na}$ escola pública de São Paulo, o contingente de alunos que informou esta correspondência foi menor $(49 \%)$. O teste qui quadrado mostrou associação positiva entre opinião parental e motivo $\left(X^{2}=112,397^{\mathrm{a}}, p<0,05\right)$. Verifica-se assim que, para a percepção da grande maioria $(91 \%)$ dos participantes, os pais manifestariam sua opinião sobre sua resolução de conflitos, assim como o motivo para tal.

Tabela 9 - Percepção da opinião dos pais por tipo de escola no conflito da humilhação.

\begin{tabular}{lcccc}
\hline & Pública SP\% & Privada SP\% & Privada MG\% & Amostra total \\
\hline Aprovariam & 67 & 78 & 77 & 73 \\
Desaprovariam & 21 & 14 & 15 & 18 \\
Não opinariam & 11 & 8 & 19 & 8 \\
Sem consenso & & & 2 & 0,8 \\
\hline
\end{tabular}

Tabela 10 - Relação entre opinião parental e motivo na situação de humilhação

\begin{tabular}{|c|c|c|c|c|c|c|c|c|}
\hline & Recomendado & $\begin{array}{c}\text { Não } \\
\text { recomendado }\end{array}$ & $\begin{array}{c}\text { Sentimento } \\
\text { Filho }\end{array}$ & $\begin{array}{l}\text { Sentimento } \\
\text { ação }\end{array}$ & Consequência & $\begin{array}{c}\text { Não } \\
\text { contaria }\end{array}$ & Outra & \\
\hline Aprovaria & $76 \%$ & $1 \%$ & $12 \%$ & $4 \%$ & $2 \%$ & & $4 \%$ & $97 \%$ \\
\hline Desaprovaria & & $69 \%$ & $12 \%$ & $12 \%$ & $3 \%$ & & $3 \%$ & $99 \%$ \\
\hline Não opinaram & $14 \%$ & $9 \%$ & $27 \%$ & $18 \%$ & $4 \%$ & $18 \%$ & $9 \%$ & $99 \%$ \\
\hline Desacordo & & $33 \%$ & & $33 \%$ & & & $33 \%$ & $99 \%$ \\
\hline
\end{tabular}


O segundo conflito em que foi solicitada a percepção da opinião de pais sobre a estratégia escolhida foi o causado pelo empurrão dado por um colega, descrito como da mesma idade e sexo que o participante, cuja intenção não é definida. Como mostra a Tabela 11, a estratégia mais frequentemente apontada neste conflito, principalmente nas escolas paulistanas foi a agressão, mais incidente no sexo masculino $(41 \%)$ do que no feminino $(30 \%)$. A agressão na maioria das respostas consistiu em empurrar o colega para fora da fila para retomar o lugar, ou adverti-lo do desrespeito por meio de gritos ou insultos. A segunda estratégia mais frequente $(24 \%)$, principalmente nas escolas paulistanas, foi a combinação de agressão com submissão, que consistiria em apelar para alguma autoridade escolar para resolver a situação. Na escola privada mineira, esta estratégia foi menos frequente. A estratégia mais desejável, que consistiria em respostas assertivas, como por exemplo, alertar o colega sobre o próprio direito ao lugar na fila foi escolhida em terceiro lugar, por $21 \%$ dos participantes, principalmente pelos de escolas privadas.

Como pode ser observado na Tabela 12, a opinião dos pais sobre a reação ao empurrão é percebida pelos participantes como favorável para as estratégias mistas de submissão e agressão, assim como para as assertivas, e desfavorável para as agressivas. Já entre os que acreditam que seus pais não opinariam sobre sua conduta, mais de um terço apontou como estratégia a agressão, e cerca de um quinto respostas assertivas. Finalmente, os que acreditam que os pais não concordariam entre si apontaram igualmente as submissas e as mistas.

Tabela 11 - Frequência das estratégias para resolver o conflito do empurrão da fila por escola

\begin{tabular}{lccc}
\hline & Pública SP $\%$ & Privada SP $\%$ & Privada MG \% \\
\hline Submissas & 2 & 10 & 7 \\
Agressivas & 40 & 36 & 33 \\
Assertivas & 14 & 19 & 21 \\
Mistas ag+sub & 28 & 24 & 20 \\
Mistas ag+as & 6 & 7 & 12 \\
Mistas as+sub & 9 & 2 & 7 \\
\hline
\end{tabular}

Tabela 12 - Proporção de opinião percebida nos pais sobre estratégias da amostra no conflito do empurrão

\begin{tabular}{lcccc}
\hline & Aprovaria \% & Desaprovaria \% & Não opinião \% & Desacordo \% \\
\hline Submissão & 7 & 2 & 5 & 25 \\
Agressão & 14 & 78 & 38 & \\
Mista sub/ag & 36 & 5 & 14 & 25 \\
Assertiva & 26 & 2 & 19 & \\
Mista ass/ag & 9 & 9 & & 25 \\
Mista sub/ass & 7 & 2 & 24 & \\
Total & 99 & 98 & 100 & 100 \\
\hline
\end{tabular}

Na Tabela 13, pode se verificar que mais da metade dos alunos, principalmente de escola privada mineira e da pública paulistana, informou acreditar que os pais aprovariam suas estratégias, enquanto contingentes semelhantes informaram acreditar que seriam reprovados, principalmente alunos da escola privada paulistana. $O$ teste de qui quadrado mostrou associação significativa $\left(X^{2}=191,973^{\mathrm{a}}, p<0,05\right)$ entre escolha da estratégia e opinião presumida dos pais, principalmente aprovação para o uso de estratégias submissas, mistas de submissão e agressão e desaprovação em relação ao uso das agressivas.

Como mostra a Tabela 14, também foi encontrada relação significativa entre percepção de opinião dos pais e motivo para ela $\left(\mathrm{X} 2=339,381^{\mathrm{a}}, \mathrm{p}<0,05\right)$, principalmente entre 
submissão, mistas de submissão e agressão e asserção com o que percebem como recomendado pelos pais, e agressão com o que não é recomendado. Observe-se que a estratégia preponderante neste conflito foi a agressão, o que explicaria a maior proporção (quase um terço) de desaprovação parental para a conduta escolhida.

Tabela 13 - Proporção de percepções da opinião parental por tipo de escola no conflito do empurrão

\begin{tabular}{lccc}
\hline & Pública SP \% & Privada SP\% & Privada MG\% \\
\hline Aprovaria & 58 & 51 & 63 \\
Desaprovaria & 33 & 31 & 32 \\
Não opinaria & 4 & 9 & 2 \\
Discordariam & 0,7 & 3 & 0,8 \\
Não resp/não sabe & 4 & 1 & 0,8 \\
Outras & & 4 & \\
\hline
\end{tabular}

Tabela 14 - Relação entre opinião parental percebida e motivo na situação do empurrão

\begin{tabular}{lccccccc}
\hline & Recomendado & $\begin{array}{c}\text { Não } \\
\text { recomendado }\end{array}$ & $\begin{array}{c}\text { Sentimento } \\
\text { participante }\end{array}$ & $\begin{array}{c}\text { Sentimento } \\
\text { ação }\end{array}$ & $\begin{array}{c}\text { Consequência } \\
\text { da ação }\end{array}$ & $\begin{array}{c}\text { Não } \\
\text { contaria }\end{array}$ & Outra \\
\hline Aprovaria & $86 \%$ & $6 \%$ & $13 \%$ & $25 \%$ & & & \\
Desaprovaria & $12 \%$ & $86 \%$ & $20 \%$ & $62 \%$ & $67 \%$ & $100 \%$ & \\
Não & $1 \%$ & $6 \%$ & $67 \%$ & $12 \%$ & $33 \%$ & & \\
opinaram & & & & & & & \\
& $99 \%$ & $98 \%$ & $100 \%$ & $99 \%$ & $100 \%$ & $100 \%$ & \\
\hline
\end{tabular}

Em suma, quanto ao objetivo principal da pesquisa, que consistiu em identificar a percepção da opinião parental para as estratégias apontadas na resolução de conflitos, assim como os motivos para as mesmas, verificou-se, em primeiro lugar, que os alunos estabelecem relação entre o que relatam que fariam e o que percebem que seus pais achariam. A maioria das justificativas apresentadas, tanto para aprovação como para reprovação, afirma a relação entre recomendações dos pais sobre como lidar com conflitos e a estratégia escolhida. Esta relação é confirmada ainda nas proporções diferentes de aprovação percebida nos pais em cada um dos dois conflitos em que foi pedida a informação sobre sua opinião.

No primeiro analisado, referente à humilhação pública, que provocou mais respostas pacíficas, notadamente de submissão (37\%) e de assertividade (22\%), verifica-se preponderância de aprovação parental $(73 \%)$. Já no conflito do empurrão dado por um colega, que provocou mais respostas categorizadas como agressivas (36\%), ou mistas de agressão e submissão (24\%), a aprovação parental não só foi menor $(55 \%)$ do que no conflito anterior, mas encontrou-se ainda 30\% de desaprovação dos pais para a ação. As justificativas para aprovação dos pais para a agressão perpetrada se apoiaram em sua maioria em argumentos de justiça retributiva, como o participante ter sido agredido pelo empurrão do colega.

Relacionado a este aspecto das recomendações parentais, é importante relatar as respostas dos participantes sobre o que seus pais os aconselhariam fazer caso enfrentassem uma situação de bullying. Mais da metade das respostas válidas (62\%) indicaram que o recomendado seria ausência de reação, mais frequente entre alunos de escola pública (66\%), seguidos pelos de escola privada paulistana $(63 \%)$ e da escola privada mineira (57\%). A ausência de reação seria aconselhada pelos pais, porque acreditariam que reagir só iria estimular os colegas a prosseguirem na perseguição. $\mathrm{O}$ segundo conselho mais encontrado $(25 \%)$ seria buscar auxílio de uma autoridade da escola, sendo mais frequente na escola privada mineira (35\%), em seguida na 
escola pública (23\%), e, bem menos na privada paulistana (9\%).

No que diz respeito à incidência destes conselhos relativamente ao sexo, verificou-se que mais alunas (66\%) do que alunos (58\%) seriam aconselhadas a não reagir. Não foram verificadas diferenças entre os dois sexos quanto à incidência de outras recomendações. Apenas uma minoria informou que seria aconselhada a se defender, sendo o maior contingente formado por alunos de escola privada paulistana (12\%) e menor nas escolas pública $(8 \%)$ e na privada mineira $(4 \%)$.

Observe-se que os alunos de escola privada paulistana foram os que mais apresentaram estratégias assertivas em outro conflito, semelhante ao do bullying por consistir em humilhação pública praticada por um grupo de pares. Neste sentido, há assim outras indicações de que os pais de alunos desta escola buscam orientá-los para se defender, o que pode contribuir para resolução mais satisfatória de seus conflitos. Um contingente bem maior de alunas (26\%) do que de alunos (9\%) informou que seria estimulada pelos pais a se defender.

\section{Discussão}

No que diz respeito ao objetivo desta pesquisa, de investigar a possibilidade de estabelecer relação entre as percepções dos alunos acerca da opinião parental sobre como resolver conflitos e as suas estratégias de resolução, verificou-se pelos resultados obtidos que estas últimas relacionam-se no sentido em que são vistas em sua maioria como coincidindo com o que percebem como aprovado por seus pais. Esta relação entre estratégia e opinião percebida seria de se esperar visto que as situações tratadas nos conflitos relacionam-se a domínios em que o controle parental é legitimado, no caso, o moral e o de segurança (Turiel, 2008).

Neste sentido, há indicações de que os pais buscam orientar os filhos para resolver conflitos desta natureza que confirmam a posição defendida por autores examinados anteriormente (Arim et al., 2010; Kakihara \& Tilton-Weaver, 2009; Gheorghiu et al., 2008; Montandón, 2005). Por outro lado, segundo as informações prestadas pelos participantes, trata-se de recomendações pouco favoráveis a desfechos pacíficos e satisfatórios. Isto porque ou enfatizam o evitar se envolver em problemas, para garantir sua segurança, ou não esclarecem como proceder por discordarem entre si no caso do participante selecionar estratégias de enfrentamento, ainda que pacíficas, como as respostas assertivas.

Outra orientação encontrada, que pode ser pouco favorável ao enfrentamento pacífico na resolução de conflitos, foi a informação prestada pelos participantes relativa ao provável conselho dos pais, caso estivessem sofrendo bullying. Nesta situação, a maioria dos alunos (62\%) informou que os pais os aconselhariam a não reagir porque, ao fazê-lo, iriam estimular os agressores a prosseguir na perseguição. Entretanto, vale relatar que, como verificaram Frisén, Hasselblad e Holmqvist (2012), reagir ao bullying, segundo suas vítimas, se revelou mais efetivo para interromper o processo do que apelar para autoridades escolares ou ignorar a provocação, que, para os participantes da presente pesquisa, seriam as recomendadas por seus pais.

Neste sentido, as informações dos participantes relativas às recomendações dos pais sobre evitar problemas ou estimular agressores indicam que as orientações que recebem enfatizam mais a segurança do que o enfrentamento pacífico e, assim, podem estimular sensação de impotência em situações de conflito, ou mesmo, no caso do sexo feminino, ter consequências sobre a autoestima (Bandeira \& Hutz, 2010).

Outra consequência possível seria as altas taxas de mortalidade de jovens envolvidos em conflitos encontradas por Ramos e Mizne (2011). Como os resultados mostraram, a tendência predominante encontrada na amostra de não enfrentar o conflito, seguindo orientações parentais para evitarem problemas e riscos, resulta provavelmente em pouca experiência em resolvê-los de modo pacífico e justo. Assim, estes jovens só conheceriam duas formas de lidar com estas situações, a luta ou fuga, como Deluty já observava no início de suas pesquisas (Deluty, 1979).

Ainda relacionado à educação dada pela família, outro aspecto a salientar refere-se a diferenças entre níveis socioeconômicos, no caso, representados pelos dois tipos de escola. Nesta pesquisa, estas diferenças mostraram-se mais atenuadas do que o verificado em pesquisas citadas anteriormente (Leme, 2004), mas, ainda assim, foram encontradas algumas 
que valem ser destacadas, como a maior tendência à agressividade e menor assertividade entre alunos de escola pública. Vale lembrar que, segundo as informações prestadas sobre constituição familiar, estes alunos provavelmente encontram mais variação em termos de práticas de socialização, porque menos da metade vive somente com a família nuclear, o que explicaria mostrarem-se menos cientes do que alunos de escola privada sobre o que pensam seus pais.

Estas informações são coerentes com os resultados relatados por Custódio e Cruz (2008) sobre as representações dos pais como menos explícitos sobre suas expectativas em níveis socioeconômicos menos afluentes. Os alunos de escola pública mostraram-se também mais pessimistas quanto à aprovação de seus pais sobre suas estratégias do que os alunos de escola privada.

Outro aspecto que pode explicar a incidência mais alta de estratégias agressivas na escola pública do que nas duas privadas é a menor oportunidade constatada nesta pesquisa que têm estes alunos de contato e estabelecimento de vínculos de amizade em atividades de lazer fora da escola. Burgess, Wojslawowics, Rubin, Rose Krasnor e Booth La-Force (2006) afirmam que amigos e colegas inspiram reações diferentes, mais conciliatórias, no caso dos primeiros e de confronto no de colegas. Estes resultados mostram que relações de amizade são consideradas em situações de conflito, principalmente no processo de atribuição de intencionalidade. Quando esta é ambígua e o perpetrador não é pessoa próxima, a intenção é interpretada como má (Goldstein, Tisak, Persson, \& Boxer, 2006).

Por outro lado, é possível que o desenvolvimento cognitivo da amostra estudada ainda não seja suficiente para lidar com toda a complexidade envolvida na situação de conflito, como apontado na introdução (Ellsworth, 1994; Vasconcellos et al., 2006). Além disso, como salientado anteriormente, as experiências que poderiam contribuir para a evolução deste desenvolvimento são restringidas pela percepção de riscos envolvidos no enfrentamento de conflitos, informado como desaconselhado pelos pais. Esta questão do desenvolvimento psicológico vale ser explorada em futuras pesquisas que busquem investigar a relação entre percepção da opinião parental e uso estratégias de resolução de conflitos em amostras com idade superior a dos participantes deste estudo.

Uma outra variável apontada anteriormente (Montandón, 2005) que também deve ser considerada para melhor compreender os resultados encontrados é o tipo de cultura em que ocorre a socialização, em termos dos valores mantidos, no presente caso aqueles relativos à convivência. Nas culturas coletivistas, como a brasileira, a harmonia entre os membros do grupo é mais valorizada do que em culturas individualistas, o que poderia explicar as informações relativas a orientações parentais no sentido de evitar riscos e problemas relatados pelos participantes.

Concluindo, há indicações de que concepções sobre relações sociais, relativas ao poder atribuído a si mesmo e ao outro para modificar as situações de desacordo, que são transmitidas no contexto da socialização interferem na percepção e na consideração de soluções possíveis para um conflito. Esta conclusão se justifica tendo em vista o constatado por Ohene et al. (2006) que verificaram que a percepção de desaprovação parental ao uso da violência relaciona-se a atitudes pró-sociais dos filhos. No caso da presente pesquisa, a opinião percebida nos pais como sendo favorável à ausência de reação e a preponderância de estratégias submissas constatada nos resultados, parece indicar interferência desta natureza.

Esclarecer a natureza da relação aqui constatada entre percepção de opinião parental e seleção de estratégia é um aspecto que consideramos importante de ser investigado em futuras pesquisas, pois, quanto menos se acredita na possibilidade de mudança (Yeager, Trzesniewski, Tirri, Nokelainen, \& Dweck, 2011) nestas relações, menos se considera a possibilidade de defesa ou negociação em situações que o permitiriam, favorecendo o convívio com o outro. Além disso, a rigidez no trato com essas questões pode levar os jovens não só a resolver insatisfatoriamente seus conflitos, mas ainda reduzir suas oportunidades de aprendizagem social.

\section{Referências}

Arim, R. G., Marshall, S. \& Shapka, J. D. (2010). A domain specific approach reporting of parental control. Journal of Adolescence, 33, 355-366. 
Ballif-Spanvill, B., Clayton, C. J., \& Hendrix S. B. (2003). Gender, types of conflict, and individual differences in the use of violent and peaceful strategies among children who have and have not witnessed interparental violence. American Journal of Orthopsychiatry, 73(2), 141-153.

Bandeira, C. M., \& Hutz, C. S. (2010). As implicações do bullying na autoestima de adolescentes. Psicologia Escolar $e$ Educacional, 14(1), 131-138.

Baumrind, D., \& Black, A. (1967). Socialization practices associated with dimensions of competence in preschool boys and girls. Child Development, 38(2), 291-397.

Baumrind, D. (1971).Current patterns of parental authority. Developmental Psychology Monographs, 4(1-2), 1-103.

Baumrind, D., Larzelere, R. E., \& Owens, E. B. (2010). Effects of preschool parents' power assertive patterns and practices on adolescent development. Parenting: Science and Practice, 10(3), 157-201.

Bergeron, N. \& Schneider, B. H. (2005). Explaining cross-national differences in peer-directed aggression: a quantitative synthesis. Aggressive Behavior, 31, 116137.

Burgess, K. B., Wojslawowics, J. C., Rubin, K. H, Rose Krasnor, L., \& Booth La-Force, C. (2006). Social information processing and coping strategies of shy/withdrawn children and aggressive children: does friendship matters? Child Development, 77(2), 371383.

Carvalho, M. C. N., \& Gomide, P. I. C. (2005). Práticas educativas parentais em famílias de adolescentes em conflito com a lei. Estudos de Psicologia. Campinas, 22(3), 263-275.

Costa, F.T.; Teixeira, M. A. P., \& Gomes, W. B. (2000). Responsividade e exigência: duas escalas para avaliar estilos parentais Psicologia Reflexão e Crítica, 13(3), 465473.

Custódio, S., \& Cruz, O. (2008). As representações mentais das crianças acerca das figuras parentais. Psicologia: Teoria $e$ Pesquisa, 24(4), 393-405.
Darling, N. Cumsille, P., \& Martínez, M. L (2008). Individual differences in adolescents' beliefs about the legitimacy of parental authority and their own obligation to obey: A longitudinal investigation. Child Development , 79, 1103-1118.

Deluty, R. H. (1979). The children's action tendency scale: A self report measure of aggressiveness, assertiveness and submissiveness in children. Journal of Consulting Psychology, 47, 1061-1071.

De Salvo, C. G., Silvares, E. M, \& Toni, P. M. (2005). Práticas educativas como forma de predição de problemas de comport amento e competência social. Estudos de Psicologia. Campinas, 22(2), 187-195.

Ellsworth, P. (1994). Sense, culture and sensibility. In S. Kitayama \& H.R. Markus (Eds.), Emotion and culture: Empirical studies of mutual influence. Washington, D.C.: American Psychological Association.

Frisén, A., Hasselblad,T., \& Holmqvist, K. (2012). What acctually makes bullying stop? Reports from former victims. Journal of Adolescence, 35, 981-990.

Gheorghiu, M. D., Gruson, P., \& Vari, J. (2008). Trocas intergeracionais e construção de fronteiras nas eperiências educativas das classes médias. Educação e Sociedade, 29(103), 377-399.

Goldstein, S. E., Tisak, M. S., Persson, A.V. \& Boxer, P. (2006). Children's evaluations of ambigous provocation by relationally aggressive, physically agressive and prosocial peers. British Journal of Developmental Psychology, 24, 701-708.

Grusec, J. E. (2011). Socialization processes in the family: social and emotional development. Annual Review of Psychology, 62, 243-269.

Grusec, J. E., \& Goodnow, J. J. (1994). Impact of parental discipline methods on the child's internalization of values: A reconceptualization of current points of view. Developmental Psychology, 30, 1, 419. 
Kakihara, F., \& Tilton-Weaver, L. (2009). Adolescents' interpretations of parental control: differentiated by domain and types of control. Child Development, 80(6), 17221738 .

Kikas, E., Peets, K, Tropp, K. \& Hinn, M. (2009). Associations between verbal reasoning, normative beliefs about aggression and different forms of aggression. Journal of Research on Adolescence, 19(1), 137-149.

Leme, M. I. S. (2004). Resolução de conflitos interpessoais: interação entre cognição e afetividade na cultura. Psicologia Reflexão e Crítica, 17(3), 367-380.

Leme, M. I. S. (2006). Cognição, Cultura e Afetividade em Solução de Problemas: Estrutura e Função. Tese de livre docência não publicada, Universidade de São Paulo, São Paulo.

Lins-Dyer, M. T., \& Nucci, L. (2007). The impact of social class and social cognitive domain on northeastern brazilian mothers' and daughters' conceptions of parental control. International Journal of Behavioral Development, 31(2), 105-114.

Maccoby, E. E. (1984). Socialization and developmental change. Child Development, 55(2), 317-328.

Martinez-Lozano,V., Sánchez-Medina, J. A., \& Goudena, P. P. (2011). A cross-cultural study of observed conflicts between young children. Journal of Cross-Cultural Psychology, 42(6), 895-907.

Montandón, C. (2005). As práticas educativas parentais e a experiência das crianças. Educação e Sociedade, 26(91), 485-507.

Noakes, M. A., \& Rinaldi, C. M. (2006). Age and gender differences in peer conflict. Journal of Youth and Adolescence, 35(6), 881-891.

Ohene, S. A., Ireland, M., Mc Neely, C. \& Borowsky, I. W. (2006). Parental expectations, physical punishment and violnce among adolescents who score positive on a social screening test im primary care. Pediatrics, 117(2), 441-447.
Prust, L. W., \& Gomide, P. I. C. (2007). Relação entre comportamento moral dos pais e dos filhos adolescentes. Estudos de Psicologia, Campinas, 24(1), 53-60.

Ramos, S., \& Mizne, D. (2011). Vulnerabilidade e Violência In C. A. Gomes (Org.), Juventudes: possibilidades e limites. (pp. 45-79). Brasília, UNESCO - UCB.

Reichert, C. B., \& Wagner, A. (2007). Autonomia na adolescência e sua relação com o estilo parental. Psico, 38(3), 292-299.

Sampaio, I. T. A., \& Gomide, P. I. C. (2007). Inventário de estilos parentais IEP - Gomide (2006). Percurso de padronização e normatização. Psicologia e Argumento, 25(48), 15-26.

Sampaio, I. T. A., \& Vieira, M. L. (2010). A influência do gênero e da ordem de nascimento sobre as práticas educativas parentais. Psicologia: Reflexão e Crítica, 23(2), 198-207.

Teixeira, M. A. P., Oliveira, A. M., \& Wottrich, S. H. (2006). Escalas de práticas parentais (EEP): Avaliando dimensões de práticas parentais em relação a adolescentes. Psicologia Reflexão e Crítica, 1(3), 433441.

Turiel, E. (2008). The development of children's orientations toward moral, social and personal orders: more than a sequence in development. Human Development, 51, 21-39.

Vasconcellos, S. J. L., Picon, P., Prochnow, L. P., \& Chittó Gauer, G. J. (2006). O processamento das informações sociais em crianças e adolescentes agressivos. Estudos de Psicologia, 11(3), 275-279.

Vincentin, V. F. (2009). Condições de vida e estilos de resolução de conflito entre adolescentes.Tese de doutorado não publicada. Universidade de São Paulo, São Paulo.

Weber, L. N. D., Prado, P. M., Viezzer, A. P., \& Brandenburg, O. J. (2004). Identificação de estilos parentais: o ponto de vista dos pais e dos filhos. Psicologia:Reflexão $e$ Crítica, 17(3), 323-331. 
Weber, L. N. D, Selig, A. G., Bernandi, M. G., \& Salvador, A. P. V. (2006). Continuidade dos estilos parentais através das geraçõestransmissão intergeracional de estilos parentais. Paidéia, 16(35), 407-414.

Yeager, D. S., Trzesniewski, K. H., Tirri, K., Nokelainen, P., \& Dweck, C. S. (2011). Adolescents' implicit theories predict desire for vengeance after peer conflicts: correlational and experimental evidence. Developmental Psychology, 47(4),10901107.
Recebido em 24 de Maio de 2012

Texto reformulado em 24 de Agosto de 2012

Aceite em 03 de Setembro de 2012

Publicado em 31 de Dezembro de 2012 